\title{
Effect of Samarium Substitution on the Structural and Magnetic Properties of Nanocrystalline Cobalt Ferrite
}

\author{
Sheena Xavier, Smitha Thankachan, Binu P. Jacob, and E. M. Mohammed \\ Research Department of Physics, Maharaja's College, Ernakulam, Kerala PIN-682011, India \\ Correspondence should be addressed to E. M. Mohammed; emmohammed_2005@yahoo.com
}

Received 29 April 2013; Accepted 1 August 2013

Academic Editor: Zhengjun Zhang

Copyright ( 2013 Sheena Xavier et al. This is an open access article distributed under the Creative Commons Attribution License, which permits unrestricted use, distribution, and reproduction in any medium, provided the original work is properly cited.

\begin{abstract}
A series of samarium-substituted cobalt ferrites $\left(\mathrm{CoFe}_{2-x} \mathrm{Sm}_{x} \mathrm{O}_{4}\right.$ with $\left.x=0.00,0.05,0.10,0.15,0.20,0.25\right)$ was synthesized by the sol-gel method. The structural characterizations of all the prepared samples were done using XRD and FTIR. These studies confirmed the formation of single-phase spinel structure in all the compositions. The increase in the value of lattice parameter with increase in samarium concentration suggests the expansion of unit cell. The Hall-Williamson analysis is used for estimating the average crystallite size and lattice strain induced due to the substitution of samarium in the prepared samples. Crystallinity and the crystallite size are observed to increase with the concentration of samarium. The surface morphology and particle size of a typical sample were determined using SEM and TEM respectively. The substitution of samarium strongly influences the magnetic characteristics, and this is confirmed from the magnetization measurements at room temperature.
\end{abstract}

\section{Introduction}

Spinel ferrite nanoparticles have attracted much attention in recent years because of their potential applications in high density magnetic recording, magnetic fluids, spintronics, data storage, and gas sensors [1-3]. Among the ferrite nanoparticles, cobalt ferrite has been widely studied due to its excellent chemical stability, mechanical hardness, reasonable saturation magnetization, and high magnetocrystalline anisotropy. These properties make it a promising candidate for many applications, namely, magnetic data storage, magnetic drug targeting, biosensors, and magnetic refrigeration [4-7].

Nanoferrites are simultaneously good magnetic and dielectric materials. These properties of the ferrites are governed by the choice of the cations and their distribution between tetrahedral and octahedral sites of the spinel lattice. The properties of the nanoferrites are also affected by the preparation conditions, chemical composition, sintering temperature, doping additives, and the method of preparation [8]. Several chemical and physical methods such as spray pyrolysis, sol-gel, coprecipitation, combustion technique, high energy milling, and so forth have been used for the fabrication of stoichiometric and chemically pure nanoferrite materials [9]. Among the available synthesis methods, solgel method has attracted much attention due to its inherent advantages of low processing temperature and homogenous reactant distribution. The products obtained by this method exhibit high crystalline quality, narrow size distribution, and uniform shape [10].

The substitution of rare-earth ions into the ferrite spinel structure has been reported to lead to structural distortions and to induce strain and thus significantly modify the magnetic and electrical properties [11, 12]. Rashad et al. [13] indicated the change in the magnetic properties of samariumsubstituted $\mathrm{CoFe}_{2} \mathrm{O}_{4}$ synthesized by citrate precursor method and the results revealed that the saturation magnetization and coercivity are decreased with the addition of $\mathrm{Sm}^{3+}$ ions. Peng et al. [14] have reported an increase in crystallite size of cobalt ferrite nanoparticles by the doping of gadolinium. Guo et al. [15] have reported that the substitution of $\mathrm{Sm}^{3+}$ in $\mathrm{NiFe}_{2} \mathrm{O}_{4}$ increases the lattice parameter and reduces the crystallite size of the materials. Tahar et al. [16] have investigated the effect of $\mathrm{Sm}^{3+}$ and $\mathrm{Gd}^{3+}$ substitution on the magnetic properties of cobalt ferrite synthesized by forced hydrolysis in polyol and reported that particle size increased slightly with rare earth substitution. Thus a systematic study on the influence 
of rare earth doping in cobalt ferrite has significance. In this paper we report the effect of substitution of $\mathrm{Fe}^{3+}$ ions by $\mathrm{Sm}^{3+}$ on the structural and magnetic properties of cobalt ferrite nanoparticles synthesized by sol-gel method.

\section{Experimental}

2.1. Synthesis. Samarium-substituted cobalt ferrite nanoparticles belonging to the series, $\mathrm{CoFe}_{2-x} \mathrm{Sm}_{x} \mathrm{O}_{4}$ with $x=0.00$, $0.05,0.10,0.15,0.20,0.25$ were synthesized by the sol-gel method. Stoichiometric ratios of cobalt nitrate, samarium nitrate and ferric nitrate (AR grade MERCK) were dissolved in ethylene glycol using a magnetic stirrer. The solution was then heated at $60^{\circ} \mathrm{C}$ for 3 hours until a wet gel of the metal nitrate was obtained. The gel was then dried at $120^{\circ} \mathrm{C}$. It self-ignites to a highly voluminous and fluffy product. The obtained powder was ground well and sintered for 4 hours in a muffle furnace at $400^{\circ} \mathrm{C}$.

2.2. Characterization. The samarium-substituted cobalt ferrite samples were characterized by using X-ray powder diffractometer (XRD, Bruker AXS D8 Advance) using $\mathrm{Cu}-\mathrm{K} \alpha$ radiation $(\lambda=1.5406 \AA)$ at $40 \mathrm{kV}$ and $35 \mathrm{~mA}$. The fourier transform infrared (FTIR) absorption spectra of the samples were recorded using FTIR spectrometer (Thermo Nicolet, Avatar 370) in the wave number range $4000-400 \mathrm{~cm}^{-1}$ with Potassium bromide $(\mathrm{KBr})$ as binder. The Scanning Electron Microscope (JEOL Model JSM-6390LV) was used to investigate the morphology of the sample. Elemental analysis was done using Energy Dispersive Spectrometer (JEOL Model JED-2300). The particle size was determined by subjecting the sample to Transmission Electron Microscopy $(\mathrm{H}-600)$ at an accelerating voltage of $80 \mathrm{kV}$. The magnetic characterization was carried out using a Vibrating Sample Magnetometer (VSM; Lakeshore 7410) at room temperature up to a maximum field of $20 \mathrm{kOe}$.

\section{Results and Discussion}

3.1. Structural Analysis. The XRD patterns of $\mathrm{CoFe}_{2-x} \mathrm{Sm}_{x} \mathrm{O}_{4}$ nanoparticles sintered at $400^{\circ} \mathrm{C}$ are depicted in Figure 1 . The XRD data agrees well with the standard values (ICDD file no. 22-1086). The diffraction peaks corresponding to (220), (311), (400), (422), (511), and (440) reflection planes and the absence of any extra peak show that all the samples have attained single-phase face-centered cubic structure. This implies that the $\mathrm{Sm}^{3+}$ ions have been completely dissolved into the spinel lattice of cobalt ferrite.

The lattice parameter " $a$ " for all the samples has been calculated for prominent peak using Bragg's equation:

$$
a=d_{\mathrm{hkl}} \sqrt{h^{2}+k^{2}+l^{2}} .
$$

The lattice parameter obtained for pure cobalt ferrite is in good agreement with the reported value [17]. The theoretical (X-ray) density was calculated using the following equation:

$$
\rho_{x}=\frac{8 M}{N a^{3}},
$$

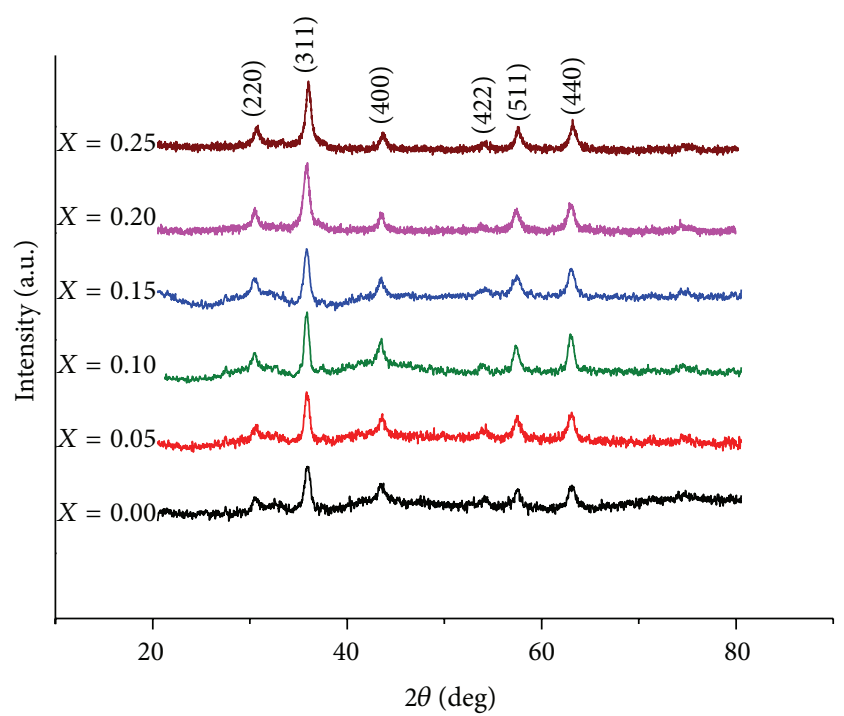

FIGURE 1: XRD patterns of $\mathrm{CoFe}_{2-x} \mathrm{Sm}_{x} \mathrm{O}_{4}$.

where $M$ is the molecular weight (gm) of the sample, $N$ is Avogadro's number (per mol), and " $a$ " is the lattice parameter in angstrom. The Hall-Williamson method is a simple but powerful tool to estimate crystallite size and lattice strain [18]. Several researchers reported the estimation of crystallite size and lattice strain of nanoferrites by using this method $[2,16]$. In this method the size-induced and strain-induced broadening of the XRD peaks is deconvoluted by considering the peak width as a function of $2 \theta$. The average crystallite size and lattice strain were calculated from the peak broadening of the XRD peaks as given below. The measured integral line width is given by

$$
\begin{gathered}
\beta_{\text {obs }}=\beta_{\text {inst }}+\beta_{\text {size }}+\beta_{\text {strain }} \\
\beta=\beta_{\text {size }}+\beta_{\text {strain }},
\end{gathered}
$$

where $\beta_{\text {obs }}$ is the observed full width at half-maximum (FWHM) from the XRD pattern. $\left(\beta_{\text {obs }}-\beta_{\text {inst }}\right)$ gives the FWHM $(\beta)$ corrected for instrumental broadening. $\beta_{\text {size }}$ and $\beta_{\text {strain }}$ are the line-broadening contributions due to crystallite size and strain, respectively. In Hall-Williamson method it is assumed that the line-broadening of a Bragg reflection originating from the small crystallite size follows Scherrer equation:

$$
\beta_{\text {size }}=\frac{K \lambda}{D \cos \theta},
$$

where $\lambda$ is the $\mathrm{X}$-ray wavelength, $K$ is the Scherrer constant $(K \approx 1), \theta$ is the Bragg angle, and $D$ is the average crystallite size. Also, the strain-induced broadening is given by the Wilson formula as

$$
\beta_{\text {strain }}=4 \varepsilon \tan \theta,
$$

where $\varepsilon$ is the root mean square value of the microstrain. Therefore (4) becomes

$$
\beta=\frac{K \lambda}{D \cos \theta}+4 \varepsilon \tan \theta .
$$


TABLE 1: Effect of $\mathrm{Sm}^{3+}$ substitution on the lattice parameter, crystallite size, X-ray density, and lattice strain of $\mathrm{CoFe}_{2-x} \mathrm{Sm}_{x} \mathrm{O}_{4}$.

\begin{tabular}{lcccc}
\hline Sm content $X$ & Lattice parameter $(\AA)$ & Crystallite size $(\mathrm{nm})$ & X-ray density $\left(\mathrm{g} \mathrm{cm}^{-3}\right)$ & Lattice strain \% \\
\hline 0.00 & 8.399 & $11.26+2.1$ & 5.260 & -0.197 \\
0.05 & 8.404 & $12.66+2.2$ & 5.357 & 0.194 \\
0.10 & 8.411 & $14.26+1.5$ & 5.449 & 0.066 \\
0.15 & 8.418 & $12.96+1.2$ & 5.541 & -0.035 \\
0.20 & 8.420 & $15.46+2.1$ & 5.642 & 0.104 \\
0.25 & 8.409 & $16.53+1.0$ & 5.769 & 0.169 \\
\hline
\end{tabular}

By rearranging the above equation, we get

$$
\beta \cos \theta=\frac{K \lambda}{D}+4 \varepsilon \sin \theta
$$

This is the Hall-Williamson equation. By plotting the value of $\beta \cos \theta$ as a function of $4 \sin \theta$ the crystallite size and lattice strain are estimated. The slope of the line gives the lattice strain $\varepsilon$ and the crystallite size $D$ can be evaluated from the intercept of this line on the $y$-axis:

$$
D=\frac{\lambda}{\text { Intercept }}
$$

The angle $\theta$ for maximum intensity and full width at half maximum $\beta_{\text {obs }}$ were determined by fitting Lorentzian profile to the prominent peaks in the XRD pattern. Hall-Williamson plots are drawn for all the samples. Figures 2(a)-2(f) depict these plots for the samples. The lattice parameter, average crystallite size, and lattice strain obtained for all the samples are given in Table 1.

It can be seen from Table 1 that the average crystallite size of the samples shows an increasing trend with the increase in the concentration of samarium. Various researchers have reported increase in crystallite size of ferrite nanoparticles by the substitution of rare earth ions $[10,14]$. The increase in the crystallite size can be considered as a good indication of improved crystallinity and great chemical homogeneity [16]. The low value of lattice strain obtained for the samariumdoped samples also indicates the improved crystallinity.

The lattice parameter of samarium-substituted cobalt ferrite is observed to be larger than that of cobalt ferrite. The lattice parameter is observed to increase up to $x=0.2$ and then decrease. An increase in lattice parameter with increase in $\mathrm{Sm}^{3+}$ ion content is expected because of the large ionic radius of $\mathrm{Sm}^{3+}(0.0964 \mathrm{~nm})$ compared to that of $\mathrm{Fe}^{3+}(0.0645 \mathrm{~nm}) . \mathrm{Sm}^{3+}$ ions are expected to enter into the octahedral sites in place of $\mathrm{Fe}^{3+}$ ions which could result in an internal stress to make the lattice distorted and an expansion of unit cell. Similar results are reported $[10,15]$. The decrease in lattice parameter for $x>0.2$ may be due to the transfer of $\mathrm{Co}^{2+}$ ions from octahedral sites to tetrahedral sites because of the increased concentration of the samarium ions $[19,20]$. It can also be seen from Figure 1 that the Bragg peak positions for the $\mathrm{Sm}^{3+}$ substituted ferrite are shifted a little to the left of the pure cobalt ferrite sample. According to Bragg's equation ( $\lambda=2 d_{\mathrm{hkl}} \sin \theta_{\mathrm{hkl}}$, where $\lambda$ is the $\mathrm{X}$-ray wavelength, $d_{\mathrm{hkl}}$ is the crystal plane spacing, and $\theta_{\mathrm{hkl}}$ is the corresponding Bragg angle), decrease in diffraction angle means an increase in the lattice parameter for the samarium-substituted cobalt ferrite [10]. We have seen that the samarium substitution has made changes in the lattice parameter and hence $d$-spacing values of the $\mathrm{CoFe}_{2-x} \mathrm{Sm}_{x} \mathrm{O}_{4}$ system, and this may probably be the reason for the observed shift of XRD peaks with samarium substitution. The theoretical (X-ray) density of cobalt ferrite is in agreement with that of the bulk cobalt ferrite [17]. It increases with increase in samarium concentration and this is expected because it mainly depends on the molecular weight.

3.2. TEM and SEM Analysis. The surface morphology and microstructure were studied using SEM that is shown in Figure 3(a). SEM image of the sample $\mathrm{CoFe}_{1.9} \mathrm{Sm}_{0.1} \mathrm{O}_{4}$ shows good homogeneity. The composition of the sample was determined by the EDS and the pattern obtained is shown in Figure 3(b). The specimen shows presence of $\mathrm{Co}, \mathrm{Fe}, \mathrm{Sm}$, and $\mathrm{O}$ in the sample and did not contain any other impurities. This indicates the purity of the prepared sample.

The TEM image of the sample $\mathrm{CoFe}_{2-x} \mathrm{Sm}_{x} \mathrm{O}_{4}$ (with $x=$ 0.1 ) is shown in Figure 4. It can be seen that most of the nanoparticles appear with almost spherical shape and are slightly agglomerated. The average particle size obtained from TEM analysis is $21 \pm 3 \mathrm{~nm}$.

3.3. FTIR Analysis. In the wave number range 1000$300 \mathrm{~cm}^{-1}$, the infrared bands of solids are usually assigned to vibration of ions in the crystal lattice. Two main broad metaloxygen bands are seen in the IR spectra of all spinels, and ferrites in particular. The highest one $v_{1}$ generally observed in the range $600-550 \mathrm{~cm}^{-1}$ corresponds to intrinsic stretching vibrations of the metal at the tetrahedral site. The lowest band $v_{2}$, usually observed in the range $450-385 \mathrm{~cm}^{-1}$, is assigned to octahedral-metal stretching [21]. FTIR spectra of the investigated $\mathrm{CoFe}_{2-x} \mathrm{Sm}_{x} \mathrm{O}_{4}$ samples in the wave number range $850-400 \mathrm{~cm}^{-1}$ are shown in Figure 5. The prominent bands $v_{1}$ and $v_{2}$ are present in all the samples. The vibrational frequencies of the IR bands are in agreement with the reported values [22]. It can be seen from Figure 5 that the values of $v_{1}$ and $v_{2}$ shift to lower-frequency side with increasing samarium content. Also a slight broadening of the absorption band $\nu_{1}$ is also noticed with increase in samarium concentration. This may be attributed to the substitution of $\mathrm{Fe}^{3+}$ ions by $\mathrm{Sm}^{3+}$ ions [10]. It is known that increasing site radius reduces the fundamental frequency and therefore the central frequency should shift towards the lower frequency 


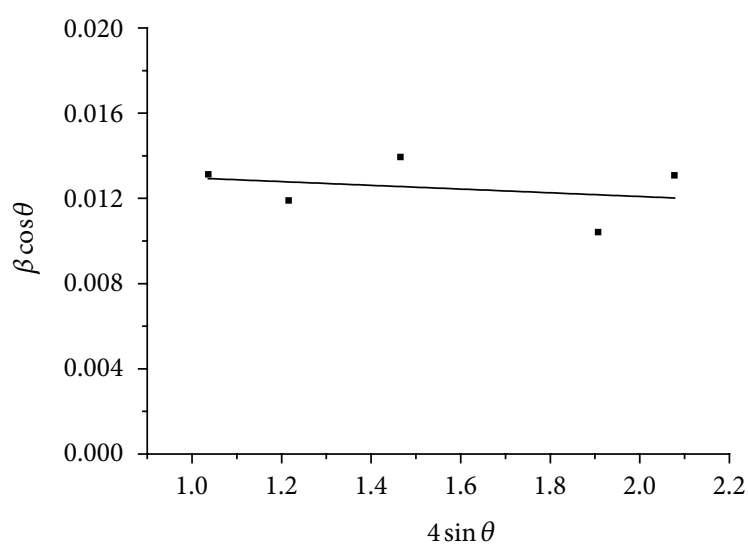

(a) $x=0.00$

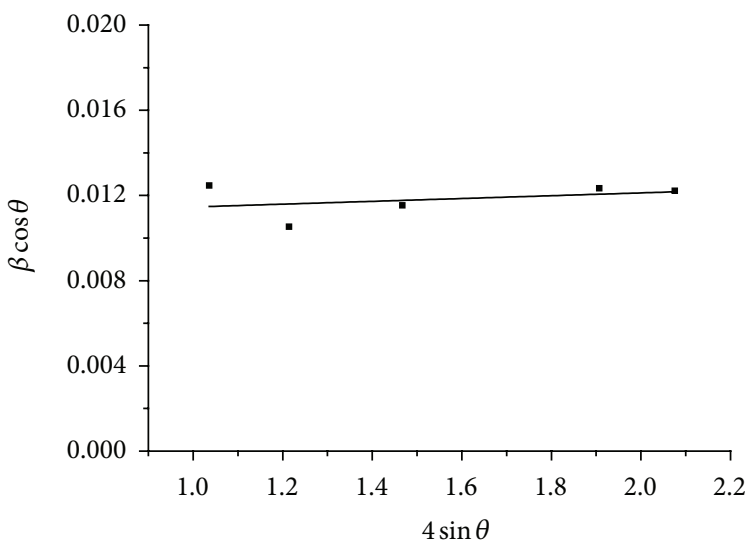

(c) $x=0.10$

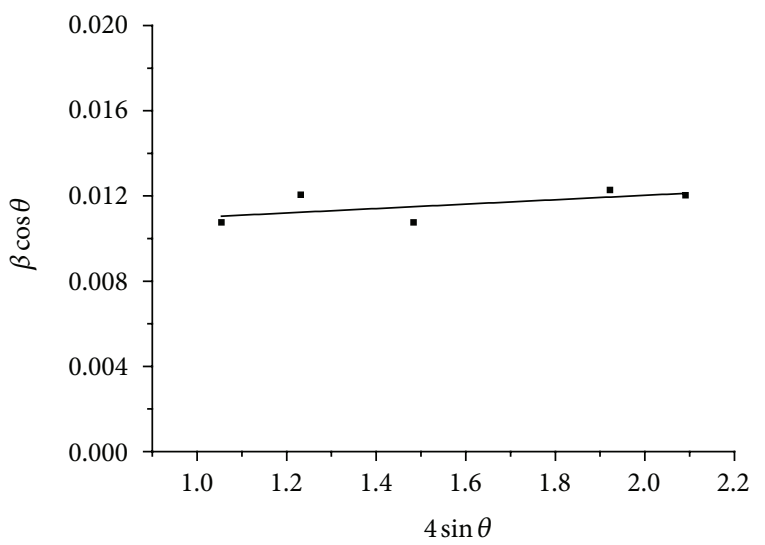

(e) $x=0.20$

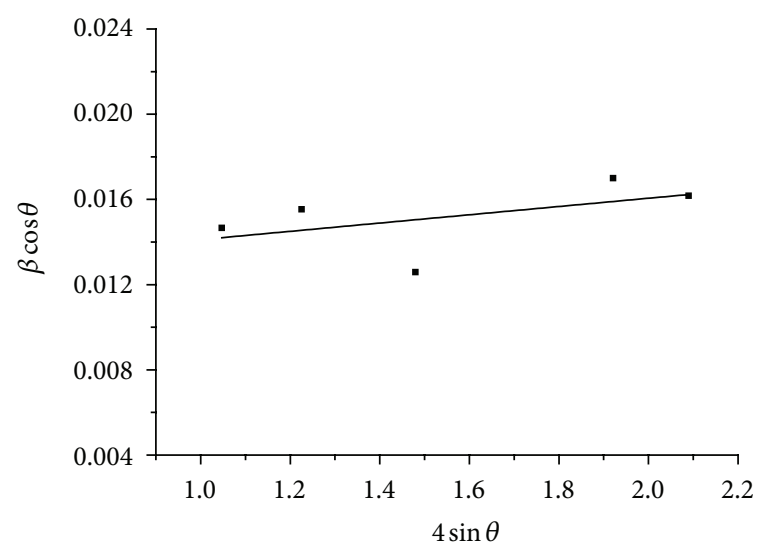

(b) $x=0.05$

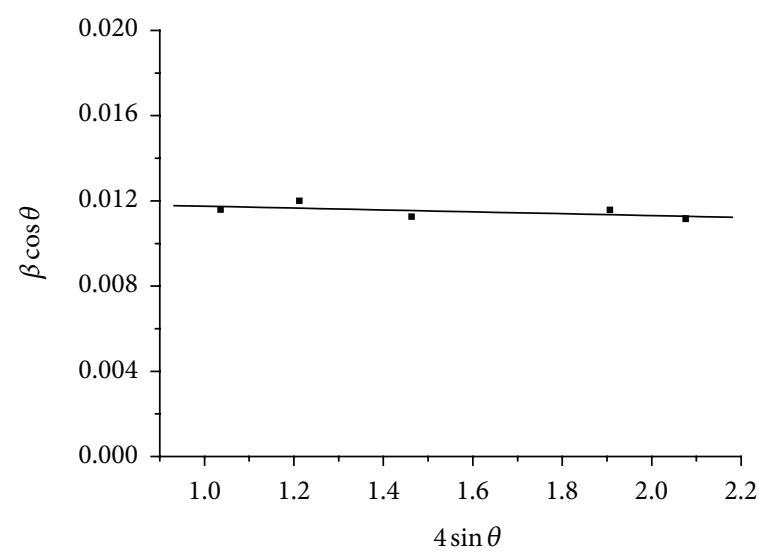

(d) $x=0.15$

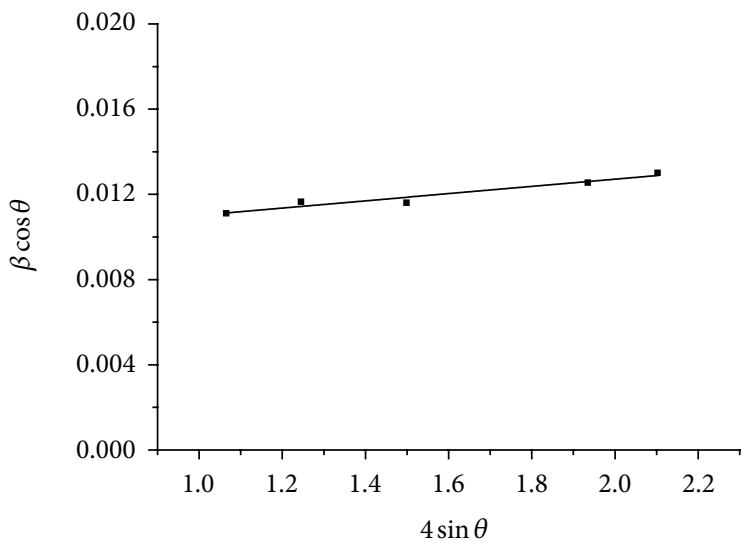

(f) $x=0.25$

Figure 2: Hall-Williamson plots for $\mathrm{CoFe}_{2-x} \mathrm{Sm}_{x} \mathrm{O}_{4}$ system.

side [23]. An increase in site radius may be expected due to the replacement of smaller $\mathrm{Fe}^{3+}$ ions by larger $\mathrm{Sm}^{3+}$ ions.

3.4. Magnetic Properties. Magnetization measurements were carried out on a vibrating sample magnetometer at room temperature with a maximum applied field of $20 \mathrm{kOe}$. Figure 6 shows the typical magnetic hysteresis loops of $\mathrm{CoFe}_{2-x} \mathrm{Sm}_{x} \mathrm{O}_{4}$ system. The saturation magnetization $M_{s}$, coercivity $H_{c}$, and remnant ratio $R$ of all the samples are presented in Table 2.

The saturation magnetization value decreases from 52.24 to $32.55 \mathrm{emu} / \mathrm{g}$ with the increase in samarium content from 0.0 to 0.25 . The value of $M_{s}$ at room temperature for the pure cobalt ferrite sample is $52.24 \mathrm{emu} / \mathrm{g}$. The low value of saturation magnetization compared with that of the bulk can be understood on the basis of core-shell model, which explains that the finite size effects of the nanoparticles lead 


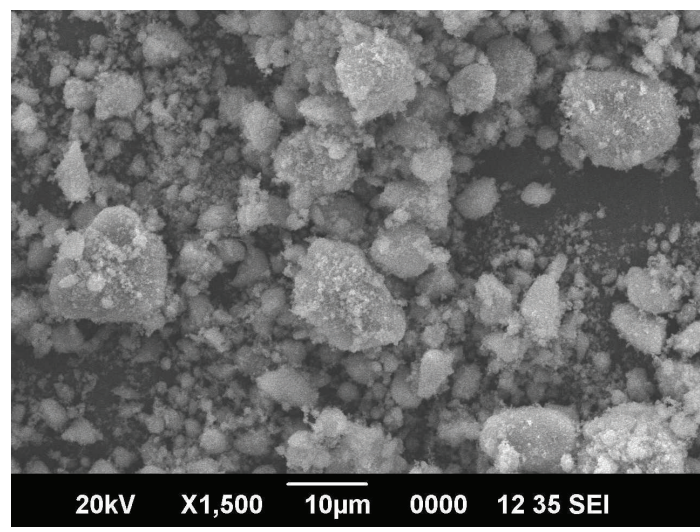

(a)

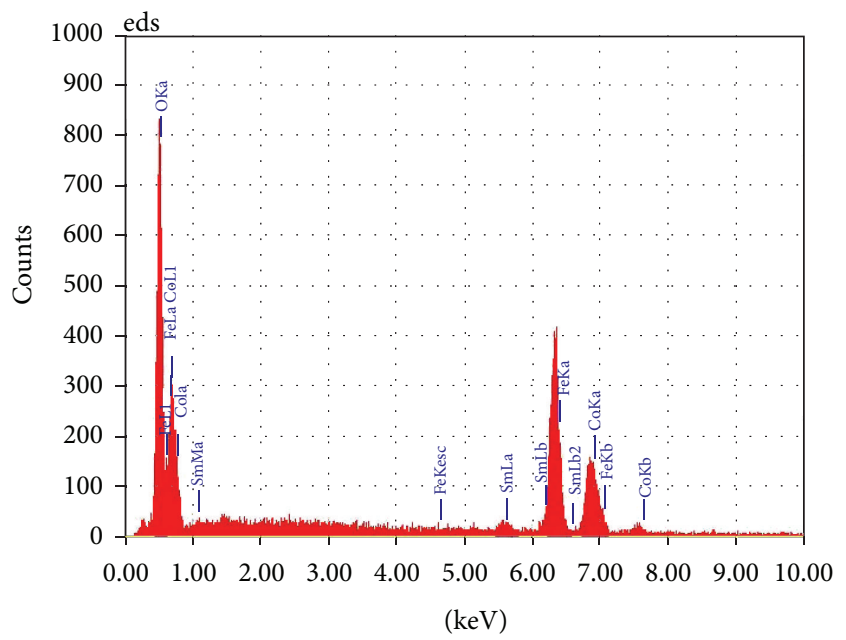

(b)

FIgure 3: (a) SEM image of the sample $\mathrm{CoFe}_{1.9} \mathrm{Sm}_{0.1} \mathrm{O}_{4}$. (b) EDS pattern of $\mathrm{CoFe}_{1.9} \mathrm{Sm}_{0.1} \mathrm{O}_{4}$.

to canting or noncollinearity of spins on their surface and thereby reduce magnetization $[24,25]$.

The net magnetic moment in the ferrite materials depends on the number of magnetic ions occupying the tetrahedral and octahedral sites. The magnetic moments of rare earth ions generally originate from the localized $4 \mathrm{f}$ electrons, and they are characterized by lower ordering temperatures, that is, less than $40 \mathrm{~K}$ [26]. Therefore, the effect of rare-earth atoms in the cobalt ferrite materials seems to be similar to the substitution of nonmagnetic atoms in the octahedral Fe sites of the spinel lattices. It is expected that the magnetization will be proportional to the effective magnetic moment of $\mathrm{Sm}^{3+}$ ions. But the substitution of $\mathrm{Fe}^{3+}$ ions by $\mathrm{Sm}^{3+}$ ions in the octahedral site decreases $\mathrm{Fe}^{3+}-\mathrm{Fe}^{3+}$ interactions. So the magnetization is decreased because of the decrease of the strong $\mathrm{Fe}^{3+}-\mathrm{Fe}^{3+}$ interactions. Therefore, samarium substitution can be considered as a nonmagnetic ion substitution in octahedral B-site and this reduces the exchange interaction between octahedral and tetrahedral sites, which results in the decrease of magnetization.

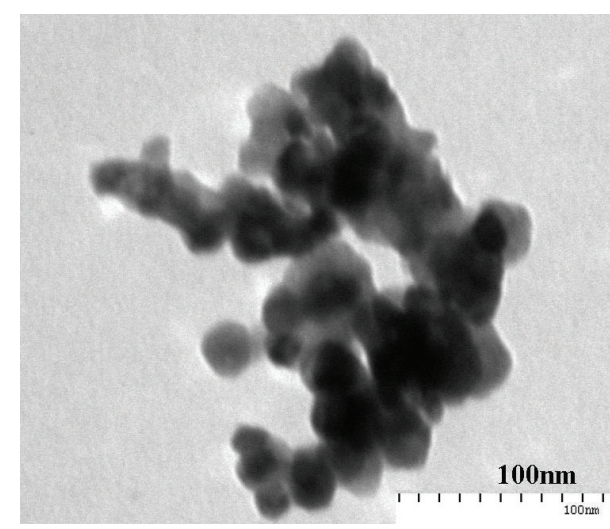

FIgURE 4: TEM image of $\mathrm{CoFe}_{1.9} \mathrm{Sm}_{0.1} \mathrm{O}_{4}$.

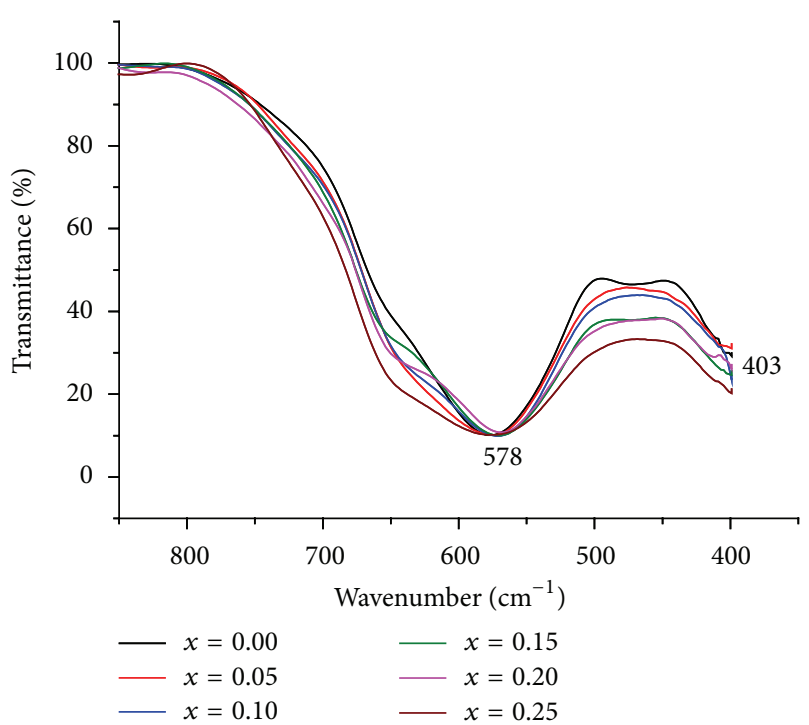

Figure 5: FTIR spectra of $\mathrm{CoFe}_{2-x} \mathrm{Sm}_{x} \mathrm{O}_{4}$.

The coercivity $H_{c}$ which measures the magnetic field strength required for overcoming anisotropy to flip the magnetic moments is clearly affected by the $\mathrm{Sm}^{3+}$ substitution. It is reported that coercivity is affected by the factors such as magnetocrystallinity, microstrain, size distribution, anisotropy, and the magnetic domain size [27, 28]. The coercivity values of the samarium-substituted cobalt ferrite samples vary from 1379.2 to 814.73 Oe. These values are much greater than that reported for rare earth-substituted cobalt ferrite samples synthesized by other methods [13, 29]. It is reported that, in the multidomain regime, the coercivity is inversely proportional to the grain size [27]. A larger grain size makes the motion of domain walls easier, and thereby the coercivity decreases. This may be the reason for the decrease in the coercivity with the increase in $\mathrm{Sm}^{3+}$ ion content. The remnant ratio $R=M_{r} / M_{s}$ is an indication of the ease with which the direction of magnetization reorients to the nearest easy axis magnetization direction after the magnetic field is removed. The values of remnant ratio of the prepared samples 
TABLE 2: Effect of $\mathrm{Sm}^{3+}$ doping on magnetic parameters of $\mathrm{CoFe}_{2-x} \mathrm{Sm}_{x} \mathrm{O}_{4}$.

\begin{tabular}{lcccc}
\hline Sm content $X$ & $M_{s}(\mathrm{emu} / \mathrm{g})$ & $M_{r}(\mathrm{emu} / \mathrm{g})$ & $H_{c}(\mathrm{Oe})$ & $R$ \\
\hline 0.00 & 52.24 & 20.07 & 1379.20 & 0.3842 \\
0.05 & 37.63 & 15.57 & 1202.80 & 0.4138 \\
0.10 & 36.65 & 12.00 & 1055.50 & 0.3274 \\
0.15 & 32.21 & 11.78 & 1025.00 & 0.3657 \\
0.20 & 35.59 & 12.65 & 972.24 & 0.3554 \\
0.25 & 32.55 & 12.00 & 814.73 & 0.3687 \\
\hline
\end{tabular}

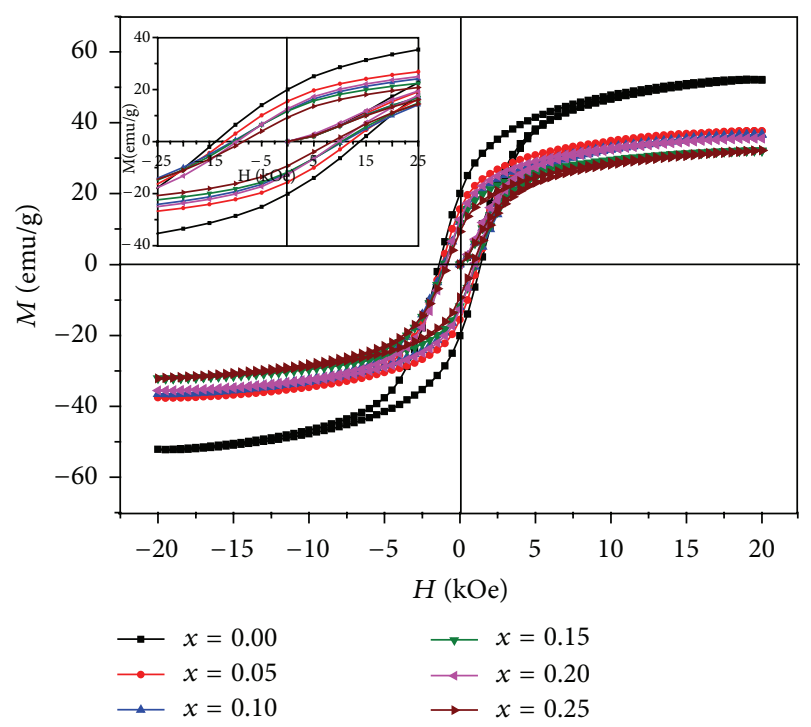

Figure 6: Room temperature hysteresis curves of $\mathrm{CoFe}_{2-x} \mathrm{Sm}_{x} \mathrm{O}_{4}$.

are in the range from 0.33 to 0.41 . This is an indication of decrease in anisotropy of the crystal lattice [30].

\section{Conclusions}

A series of samarium-substituted cobalt ferrites, $\mathrm{CoFe}_{2-x} \mathrm{Sm}_{x} \mathrm{O}_{4}$ with $x=0.00,0.05,0.10,0.15,0.20$, 0.25 were synthesized by using sol-gel method. XRD analysis confirmed the formation of single-phase spinel structure, without any secondary phase in all the compositions. The substitution of samarium in cobalt ferrite has resulted in an increase in lattice parameter and crystallite size. The decrease in lattice parameter for $x>0.2$ indicates a possible cationic redistribution. The low values of the lattice strain induced due to samarium doping indicate improved crystallinity of the sample. The prepared nanoparticles have spherical morphology, and narrow size distribution and are slightly agglomerated as evident from TEM analysis. The expected stoichiometry of the sample was confirmed by the EDS analysis. The absorption bands in FTIR spectra of all the samples are found in the expected range. The band frequencies decrease with increase in samarium content and this suggests the occupancy of $\mathrm{Sm}^{3+}$ ions on the octahedral sites. The saturation magnetization decreased with an increase in samarium content and this is attributed to the decrease in the net magnetic moment due to the substitution of nonmagnetic ion in the octahedral site. The change in coercivity with samarium content is explained based on the variation of coercivity of nanoparticles in the multidomain regime. These investigations suggest that the properties of the cobalt ferrite nanoparticles substituted with samarium ions can be tailored for suitable applications.

\section{Acknowledgments}

Sheena Xavier acknowledges the University Grants Commission of India for providing teacher fellowship. E. M. Mohammed thanks DST and UGC for the financial support. The author thank SAIF, CUSAT Kochi, SAIF, IIT Madras, and SCTIMST, Thiruvananthapuram for providing XRD, FTIR, VSM, and TEM measurement facilities.

\section{References}

[1] B. P. Jacob, S. Thankachan, S. Xavier, and E. M. Mohammed, "Dielectric behaviour and AC conductivity of $\mathrm{Tb}^{3+}$ doped $\mathrm{Ni}_{0.4} \mathrm{Zn}_{0.6} \mathrm{Fe}_{2} \mathrm{O}_{4}$ nanoparticles," Journal of Alloys and Compounds, vol. 541, pp. 29-35, 2012.

[2] S. Thankachan, B. P. Jacob, S. Xavier, and E. M. Mohammed, "Effect of neodymium substitution on structural and magnetic properties of magnesium ferrite nanoparticles," Physica Scripta, vol. 87, no. 2, Article ID 025701, 2013.

[3] L. B. Tahar, M. Artus, S. Ammar et al., "Magnetic properties of $\mathrm{CoFe}_{1.9} \mathrm{RE}_{0.1} \mathrm{O}_{4}$ nanoparticles $(\mathrm{RE}=\mathrm{La}, \mathrm{Ce}, \mathrm{Nd}, \mathrm{Sm}, \mathrm{Eu}, \mathrm{Gd}$, $\mathrm{Tb}, \mathrm{Ho}$ ) prepared in polyol," Journal of Magnetism and Magnetic Materials, vol. 320, no. 23, pp. 3242-3250, 2008.

[4] E. V. Gopalan, P. A. Joy, I. A. Al-Omari, D. S. Kumar, Y. Yoshida, and M. R. Anantharaman, "On the structural, magnetic and electrical properties of sol-gel derived nanosized cobalt ferrite," Journal of Alloys and Compounds, vol. 485, no. 1-2, pp. 711-717, 2009.

[5] B. G. Toksha, S. E. Shirsath, S. M. Patange, and K. M. Jadhav, "Structural investigations and magnetic properties of cobalt ferrite nanoparticles prepared by sol-gel auto combustion method," Solid State Communications, vol. 147, no. 11-12, pp. 479-483, 2008.

[6] Z. Zi, Y. Sun, X. Zhu, Z. Yang, J. Dai, and W. Song, "Synthesis and magnetic properties of $\mathrm{CoFe}_{2} \mathrm{O}_{4}$ ferrite nanoparticles," Journal of Magnetism and Magnetic Materials, vol. 321, no. 9, pp. 12511255, 2009.

[7] E. V. Gopalan, I. A. Al-Omari, D. S. Kumar, Y. Yoshida, P. A. Joy, and M. R. Anantharaman, "Inverse magnetocaloric effect in solgel derived nanosized cobalt ferrite," Applied Physics A, vol. 99, no. 2, pp. 497-503, 2010.

[8] I. H. Gul and A. Maqsood, "Structural, magnetic and electrical properties of cobalt ferrites prepared by the sol-gel route," Journal of Alloys and Compounds, vol. 465, no. 1-2, pp. 227-231, 2008.

[9] P. Kumar, S. K. Sharma, M. Knobel, and M. Singh, "Effect of La ${ }^{3+}$ doping on the electric, dielectric and magnetic properties of cobalt ferrite processed by co-precipitation technique," Journal of Alloys and Compounds, vol. 508, no. 1, pp. 115-118, 2010.

[10] B. P. Jacob, S. Thankachan, S. Xavier, and E. M. Mohammed, "Effect of $\mathrm{Gd}^{3+}$ doping on the structural and magnetic properties of nanocrystalline Ni-Cd mixed ferrite," Physica Scripta, vol. 84, no. 4, Article ID 045702, 2011. 
[11] K. K. Bharathi, J. A. Chelvane, and G. Markandeyulu, "Magnetoelectric properties of Gd and Nd-doped nickel ferrite," Journal of Magnetism and Magnetic Materials, vol. 321, no. 22, pp. 3677$3680,2009$.

[12] E. E. Sileo and S. E. Jacobo, "Gadolinium-nickel ferrites prepared from metal citrates precursors," Physica B, vol. 354, no. 1-4, pp. 241-245, 2004.

[13] M. M. Rashad, R. M. Mohamed, and H. El-Shall, "Magnetic properties of nanocrystalline Sm-substituted $\mathrm{CoFe}_{2} \mathrm{O}_{4}$ synthesized by citrate precursor method," Journal of Materials Processing Technology, vol. 198, no. 1-3, pp. 139-146, 2008.

[14] J. Peng, M. Hojamberdiev, Y. Xu, B. Cao, J. Wang, and $\mathrm{H}$. Wu, "Hydrothermal synthesis and magnetic properties of gadolinium-doped $\mathrm{CoFe}_{2} \mathrm{O}_{4}$ nanoparticles," Journal of Magnetism and Magnetic Materials, vol. 323, no. 1, pp. 133-138, 2011.

[15] L. Guo, X. Shen, X. Meng, and Y. Feng, "Effect of Sm ${ }^{3+}$ ions doping on structure and magnetic properties of nanocrystalline $\mathrm{NiFe}_{2} \mathrm{O}_{4}$ fibers," Journal of Alloys and Compounds, vol. 490, no. 1-2, pp. 301-306, 2010.

[16] L. B. Tahar, L. S. Smiri, M. Artus et al., "Characterization and magnetic properties of Sm- and Gd-substituted $\mathrm{CoFe}_{2} \mathrm{O}_{4}$ nanoparticles prepared by forced hydrolysis in polyol," Materials Research Bulletin, vol. 42, no. 11, pp. 1888-1896, 2007.

[17] J. Smit and H. P. J. Wijn, Ferrites, Philips Technical Library, Eindhoven, The Netherlands, 1959.

[18] G. K. Williamson and W. H. Hall, "X-ray line broadening from filed aluminium and wolfram," Acta Metallurgica, vol. 1, no. 1, pp. 22-31, 1953.

[19] M. A. Khan, M. U. Islam, M. Ishaque, I. Z. Rahman, A. Genson, and S. Hampshire, "Structural and physical properties of NiTb-Fe-O system," Materials Characterization, vol. 60, no. 1, pp. 73-78, 2009.

[20] H. E. Zhang, B. F. Zhang, G. F. Wang, X. H. Dong, and Y. Gao, "The structure and magnetic properties of $\mathrm{Zn}_{1-x} \mathrm{NixFe}_{2} \mathrm{O}_{4}$ ferrite nanoparticles prepared by sol-gel auto-combustion," Journal of Magnetism and Magnetic Materials, vol. 312, no. 1, pp. 126-130, 2007.

[21] R. D. Waldron, "Infrared spectra of ferrites," Physical Review, vol. 99, no. 6, pp. 1727-1735, 1955.

[22] N. Rezlescu, E. Rezlescu, C. Pasnicu, and M. L. Craus, "Effects of the rare-earth ions on some properties of a nickel-zinc ferrite," Journal of Physics Condensed Matter, vol. 6, no. 29, pp. 57075716, 1994.

[23] K. B. Modi, M. K. Rangolia, M. C. Chhantbar, and H. H. Joshi, "Study of infrared spectroscopy and elastic properties of fine and coarse grained nickel-cadmium ferrites," Journal of Materials Science, vol. 41, no. 22, pp. 7308-7318, 2006.

[24] P. Priyadharsini, A. Pradeep, P. S. Rao, and G. Chandrasekaran, "Structural, spectroscopic and magnetic study of nanocrystalline Ni-Zn ferrites," Materials Chemistry and Physics, vol. 116, no. 1, pp. 207-213, 2009.

[25] R. H. Kodama, "Magnetic nanoparticles," Journal of Magnetism and Magnetic Materials, vol. 200, no. 1, pp. 359-372, 1999.

[26] R. N. Panda, J. C. Shih, and T. S. Chin, "Magnetic properties of nano-crystalline Gd- or Pr-substituted $\mathrm{CoFe}_{2} \mathrm{O}_{4}$ synthesized by the citrate precursor technique," Journal of Magnetism and Magnetic Materials, vol. 257, no. 1, pp. 79-86, 2003.

[27] S. Chakraverty and M. Bandyopadhyay, "Coercivity of magnetic nanoparticles: a stochastic model," Journal of Physics Condensed Matter, vol. 19, no. 21, Article ID 216201, 2007.
[28] J. Jing, L. Liangchao, and X. Feng, "Structural analysis and magnetic properties of $\mathrm{Gd}$-doped Li-Ni ferrites prepared using rheological phase reaction method," Journal of Rare Earths, vol. 25, no. 1, pp. 79-83, 2007.

[29] L. Zhao, H. Yang, X. Zhao, L. Yu, Y. Cui, and S. Feng, "Magnetic properties of $\mathrm{CoFe}_{2} \mathrm{O}_{4}$ ferrite doped with rare earth ion," Materials Letters, vol. 60, no. 1, pp. 1-6, 2006.

[30] S. E. Shirsath, B. G. Toksha, and K. M. Jadhav, "Structural and magnetic properties of $\mathrm{In}^{3+}$ substituted $\mathrm{NiFe}_{2} \mathrm{O}_{4}$," Materials Chemistry and Physics, vol. 117, no. 1, pp. 163-168, 2009. 

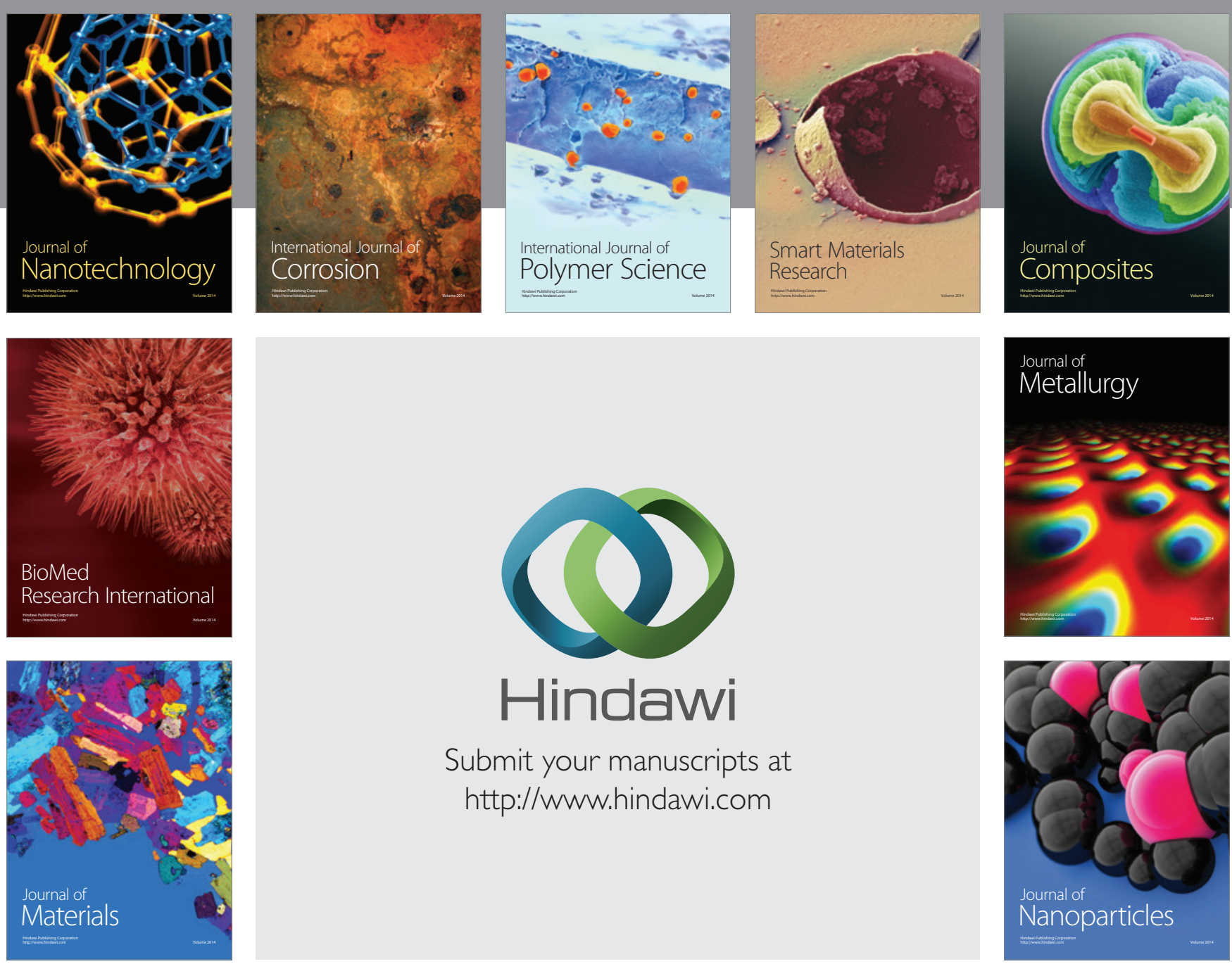

Submit your manuscripts at http://www.hindawi.com
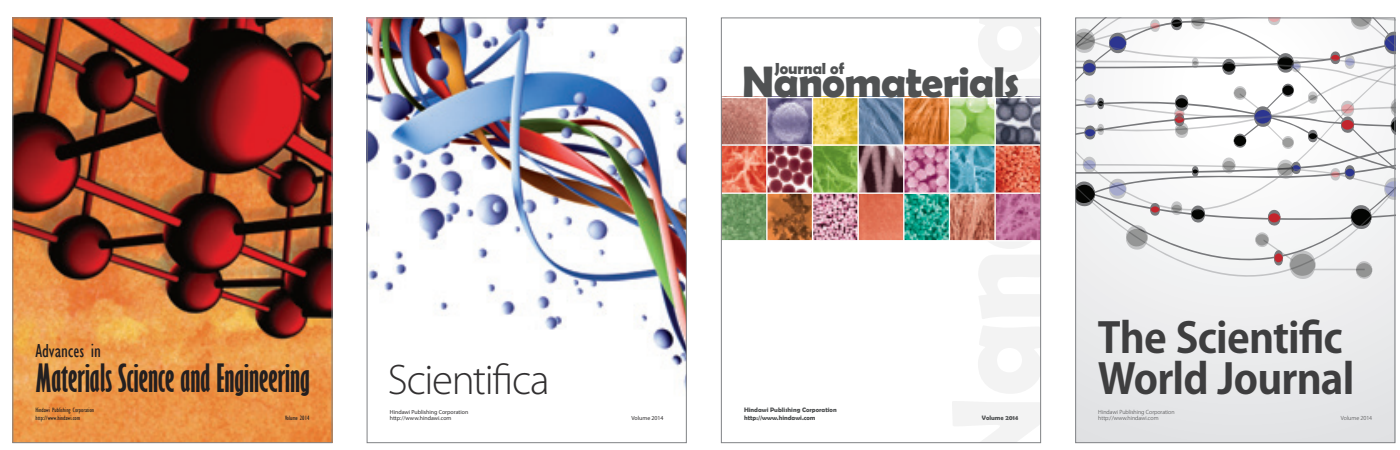

\section{The Scientific World Journal}
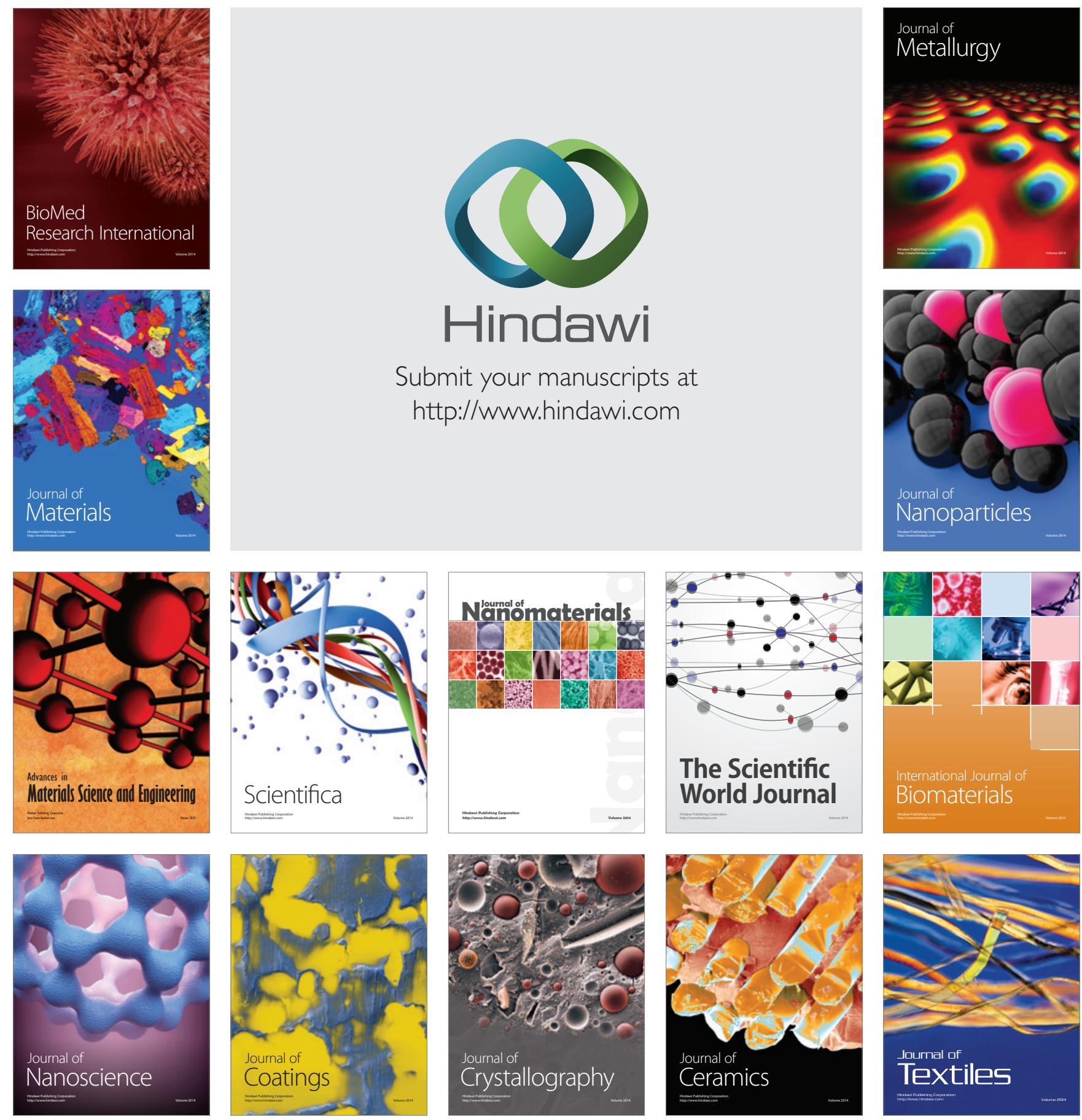